\title{
The construction of digital inheritance and preservation method for Ansai waist drum
}

\author{
Ying Guo ${ }^{1}$, Xupeng Wang ${ }^{1 *}$, Ruikun $\mathrm{Li}^{1}$ \\ ${ }^{1}$ Department of Industrial Design, Xi'an University of Technology, Xi' an Shaanxi, 710048, China
}

\begin{abstract}
An effective digital method to promote the inheritance and preservation of Ansai waist drum is introduced. The method is based on multiple technologies such as motion capture, experiment, database, as well as system development are comprehensively applied, in order to finish the construction of digital learning system, which includes architecture of system logic, construction of action information database, and functional modules design of the system such as action information module, template action animation module, data acquisition module, and evaluation module of learning action, as well as the user interface design. The method is also useful for other dance and sport national intangible cultural heritage.
\end{abstract}

\section{Introduction}

Ansai waist drum is a collection of dance, gymnastics, percussion, wind, martial arts, folk songs in one, known as "China's first drum", and was listed in the first batch of national intangible cultural heritage on May 20, 2006 [1]. Although Ansai waist drum is famous at home and abroad, there are many problems in its inheritance and protection, such as a single way of inheritance. Mentorship and family inheritance are the main forms of inheritance of Ansai waist drum [2]. The ancient traditional playing method is in danger of being lost[3]. Too much emphasis is placed on commercial development, and the role of waist drum changes from the past blessing ceremony to the secular utilitarian, which makes the $\mathrm{Wu}$ waist drum, which represents the symbol of war, gradually lose its inheritance [4]. These problems have seriously hindered the inheritance and protection of Ansai waist drum, and need to be addressed anxiously.

The study of non-material cultural heritage digital starts early abroad, for example, Japan established the non-material cultural heritage preservation system in the 1950s [5]. In the 1970s, the American library established "folklore protection center", which is dedicated to digitization of folk culture. Marcello $\mathrm{C}$ et al. finished digital display and demonstration teaching of traditional crafts such as handicrafts and sculpture through $3 \mathrm{~d}$ virtual interactive platform [6]. Jacky $\mathrm{C}$ et al. developed a dance teaching system, which used motion capture and virtual reality technology to capture and analyze students' dance movements, and provided feedback and achieved interactive learning [7].

Compared with foreign countries, the research on the digitization of intangible cultural heritage started late in China, but it has been carried out gradually and has made many achievements. With the help of motion capture technology and 3d animation technology, Shi Lei conducted interactive display and digital protection research on flower waist dance [8]. Based on motion capture technology, Yu Tao input the standard movement data of 24-style Taijiquan in a standardized way, and established a number of standard 24-style TaiJiQuan movement data sets [9]. Chen Junxi designed a multiplatform interactive Gangling paper-cutting game based on $\mathrm{Html} 5$ by means of virtual man-machine interaction, so as to realize the dissemination and protection of Gangling paper-cutting art [10].

The paper focuses on introducing a method for digital inheritance and preservation of Ansai waist drum based on motion capture technology. The second part of the paper introduces the construction of metadata database for digital inheritance. The third part is digital inheritance system construction, which contains the document library module, the inheritor information module, the action information database module, the performing arts database module, and the costume music module, as well as the interactive practice module. And the fourth part is the conclusion of this paper.

\section{Construction of metadata database}

The metadata description method, which is used in geographic information systems, is introduced in the paper to Ansai waist drum tradition involved in theme, content and characteristics of digital object properties such as the standardized description. At the same time, the metadata set of digital inheritance of Ansai waist drum was developed by referring to the feature classification norms of the intangible cultural heritage of sports and dance in the existing research. As shown in table 1 for the digital metadata specification table. 
Table 1. Specification table of digital metadata of Ansai waist drum motion

\begin{tabular}{|c|c|c|}
\hline Main title & subtitle & instructions \\
\hline \multirow{2}{*}{ Action } & Action name & The official name of the action \\
\hline & The alias & The dialect name of the action \\
\hline \multirow[t]{3}{*}{$\begin{array}{l}\text { Action information } \\
\text { description }\end{array}$} & $\begin{array}{l}\text { Spatial temporal } \\
\text { description }\end{array}$ & $\begin{array}{l}\text { The place where the action is distributed or } \\
\text { popular in a certain period of time, including the } \\
\text { time of origin, place of origin, time of } \\
\text { inheritance, place of inheritance and other } \\
\text { information. }\end{array}$ \\
\hline & Action description & $\begin{array}{l}\text { The action of a brief introduction, session, } \\
\text { summary, etc }\end{array}$ \\
\hline & Detail description & Action detailed rhythmic action description \\
\hline others & & Extended use \\
\hline
\end{tabular}

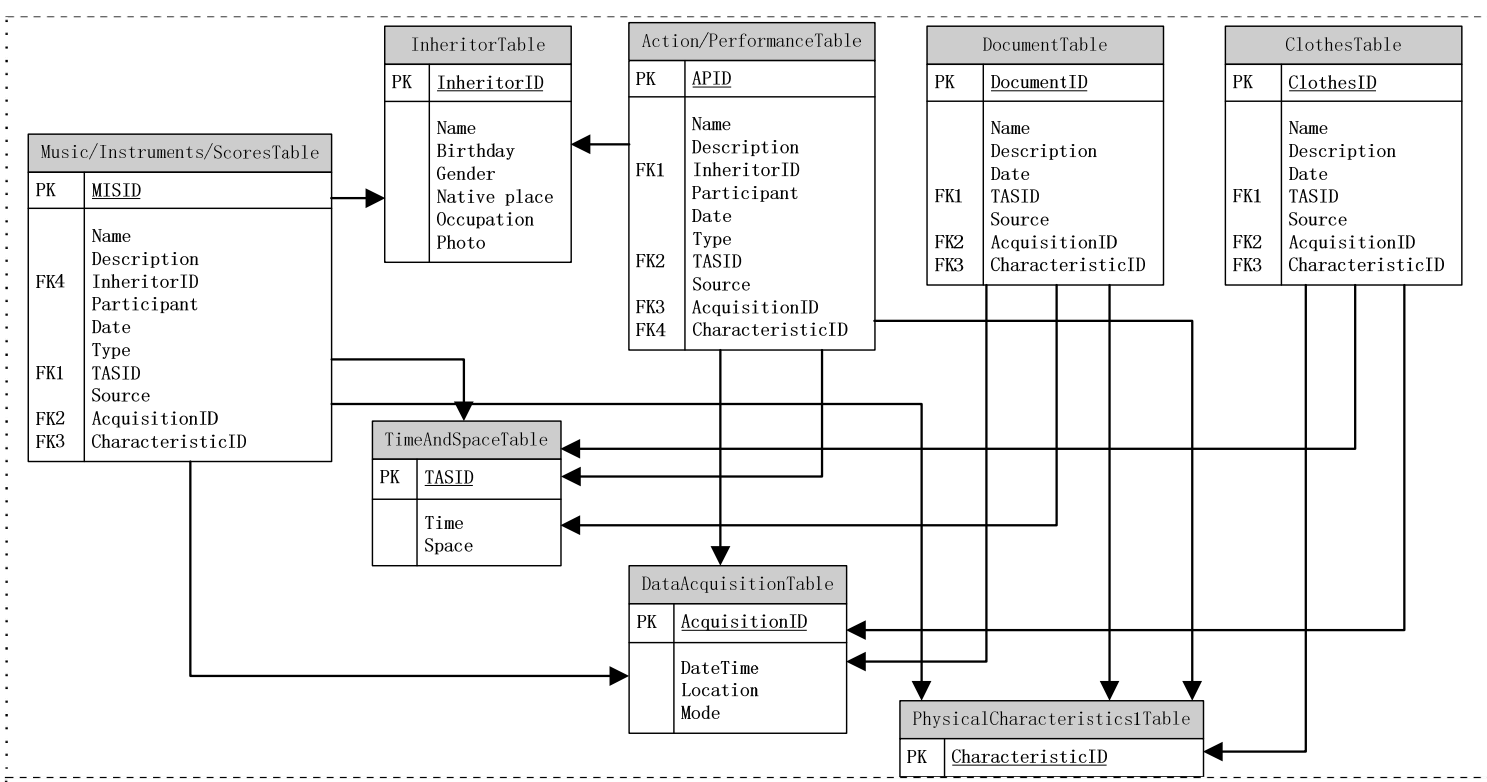

Figure 1. Structure diagram of digital inheritance metadata.

The corresponding metadata design can be carried out according to the Table 1. Then corresponding data Table was customized for each digital object, including Action/Performance Table, Inheritor Table, Music/Instruments/Score Table, Clothes Table, and Document Table. And the metadata information were added to obtain the digital inheritance meta-database structure diagram as shown in Figure 1.

The relation between each table, and the meaning of the fields in the table can be clearly identified through the metadata structure diagram. In addition, relevant digital resources in Ansai waist drum can be added and updated to the corresponding field in the table if needed.

\section{Construction of digital inheritance system}

In order to overcome the disadvantage of traditional transmission method for Ansai waist drum, the paper proposes to design the digital inheritance system as shown in Figure 2, which is divided into 6 modules, the document library module, the inheritor information module, action information database module, the performing arts database module, the costume music module, and the interactive practice module. 


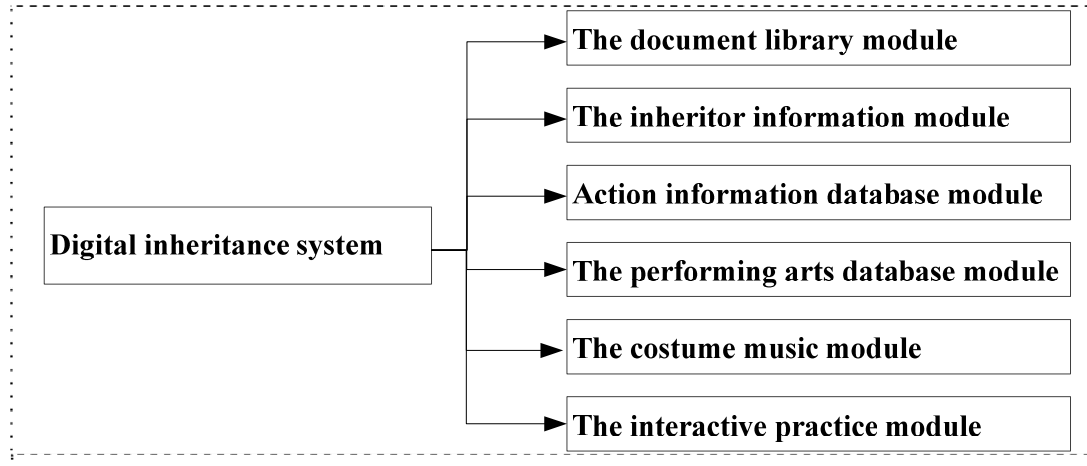

Figure 2. Structure diagram of digital inheritance metadata.

With the help of the system, users can easy to use variety of ways such as sound, images, text, music, and interactive operation et al. to complete the following work, which contains literature review of Ansai waist drum, Ansai waist drum action skill learning, Ansai drum costume show appreciation, Information of the inheritor of Ansai waist drum, Ansai drum instrument/music information learning, as well as the interactive practice of Ansai waist drum. All these can help users understand the origin, development and changes of Ansai waist drum more comprehensively and fully, and greatly enhance the fun and autonomy of user learning.

\subsection{The document library module}

The contents in the Document Table as shown in Figure 1 are shown in this module, which can be used for digital storage, update, retrieval and download of the data in the inheritance of Ansai waist drum. The purpose is to realize the digital protection and inheritance of historical data, which involves the development history, inheritance, protection, and other aspects of Ansai waist drum policy and research documents, as well as a large number of documents in the intangible cultural heritage and census process.

\subsection{The inheritor information module}

This module shows the contents in the Meta-database Inheritor table as shown in Figure 1, including the retrieval, browse and update of the inheritor of Ansai drum, which synchronously looks at the relevant data such as the inheritor's name, date of birth, gender, place of origin, occupation, photo, inheritance action, inherit music, performing arts masterpiece, inheriting the status quo and so on.

\subsection{Action information database module}

The module contains the body Action content, which is one of the important modules of Ansai waist drum digital inheritance system as shown in the Action/Performance Table of Figure 1. The body actions spatio-temporal data were collected by the motion capture system as shown in Figure 3, the common motion data formats are .C3d and. $\mathrm{BVH}$, which can visually show the limb joints in time space coordinates.

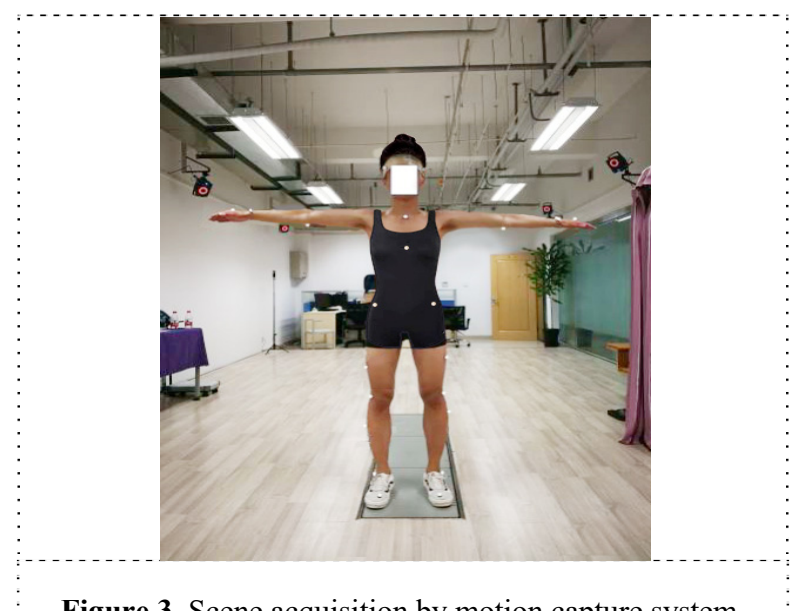

Figure 3. Scene acquisition by motion capture system.

The motion builder is used to deal with the action capture data, and then it can be bound to the mannequin made by Maya. The body actions information library can be made by matching the drumbeat, as shown in Figure 4 Users can search and browse for each action animation and movement technique, and simultaneously understand the information of the inheritor, origin, development, stage of performance et al. 


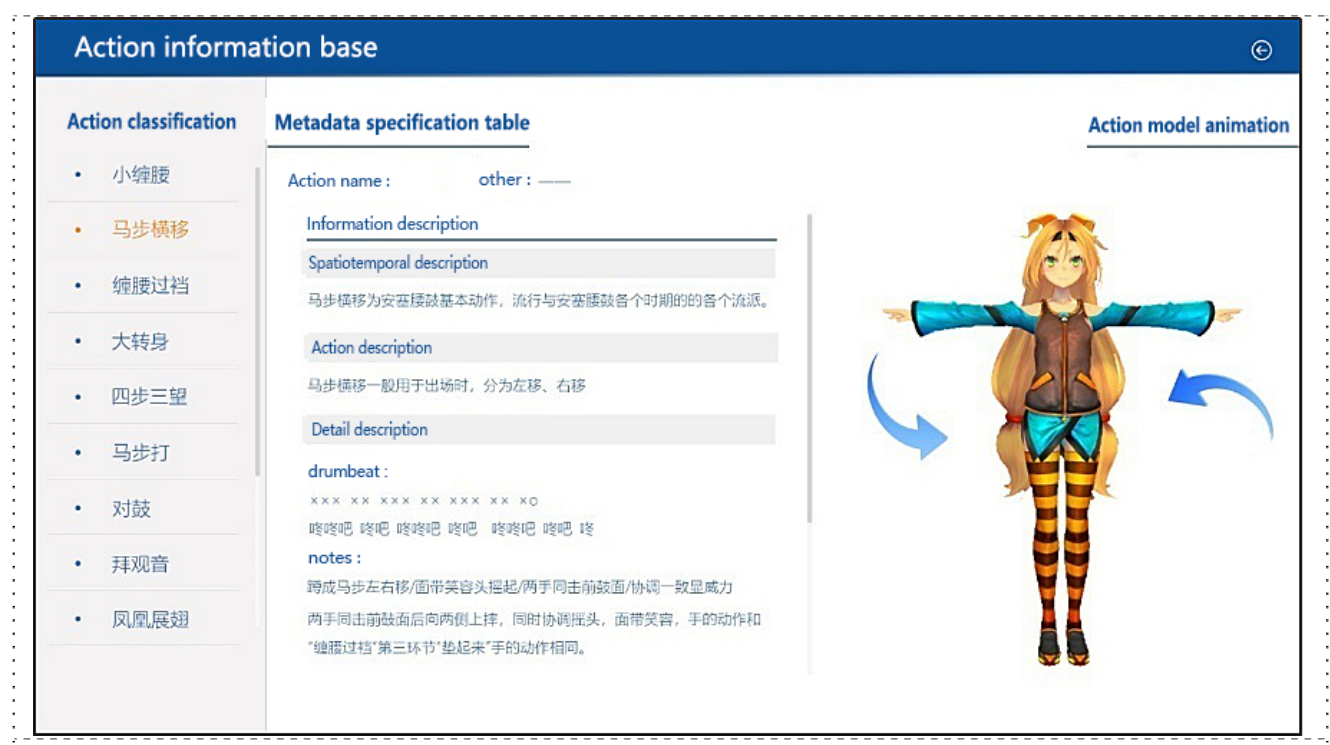

Figure 4. The action information database.

\subsection{The performing arts database module}

This module is divided into two parts, the one is clothing and the other is music. Figure 1 shows the costume display contents in the meta-database Clothes Table, which includes clothing pictures, 3D model browsing and pattern information browsing.

\subsection{The costume music module}

This module presents the performance information content in the Action/Performance Table in the metadata database as shown in figure 1, which is used to retrieve, synchronize or replay the video materials recorded in the process of performing arts, and learn about the origin, development and evolution of the performance project and other information. Furthermore, the contents in the Music/Instruments/Score Table include the browsing and retrieval of digital Score images, the browsing and retrieval of digital instrument pictures and $3 \mathrm{~d}$ models, as well as the retrieval and listening of digital Music.

\subsection{The interactive practice module}

Interactive practice module is another important module of Ansai waist drum digital inheritance system. Based on the information in the system metadata database, it mainly has the following three functions, interaction learning of action, costume design, and action choreography.

As shown in Figure 5, with the help of the action interactive learning library, using the portable motion capture device (such as Kinect) is used for man-machine interactive learning, and the teaching evaluation of human posture, motion similarity and joint angle is conducted. At the same time, users can customize the multi-channel design waist drum clothing, and save print. In addition, Users can re-arrange the waist drum action and positioning in the system, and make soundtrack editing, save after preview confirmation. This module further increases the autonomy, interestingness and practicability of Ansai waist drum digital system.

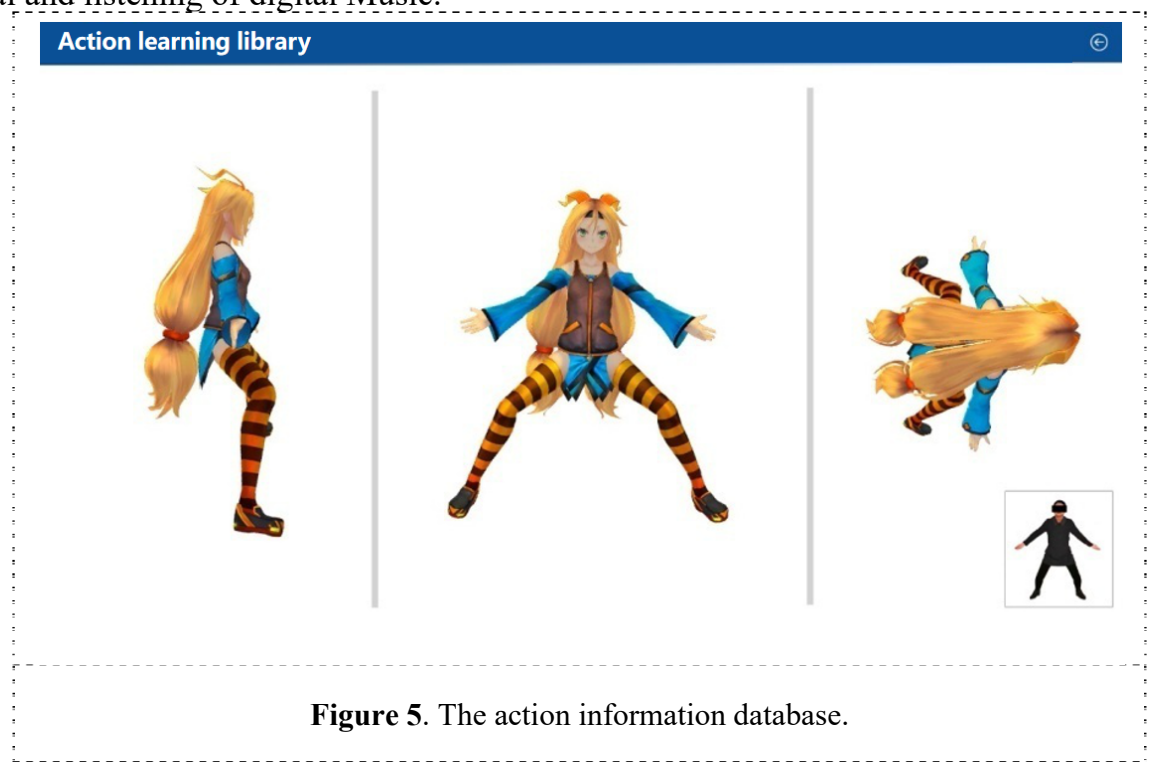




\section{Conclusion}

The paper proposes a digital inheritance method for Ansai waist drum and constructs the corresponding metadata and digital system. With the help of motion capture, database, system development and many other technologies, the system integrates text, image, sound display and interactive action learning functions and so on into one, and transmits to users a richer and more vivid Ansai drum inheritance information, which enables users to receive information through multi-sensory stimulation, accelerates users' understanding and acceptance of knowledge information related to Ansai drum, stimulates users' interest and attention to pay attention to and learn Ansai drum, and effectively promotes the inheritance and protection of Ansai drum. And the method separates the inheritance of Ansai waist drum from the traditional model, and realizes the combination of tradition and science and technology. It is not only a new attempt in the form of Ansai waist drum protection and inheritance, but also provides a certain reference for the inheritance and protection of other intangible cultural heritage projects such as sports and dance.

\section{Acknowledgments}

This work was supported by Research Foundation of the major theoretical and practical problems of Social Sciences in Shaanxi Province (Grant No. 2019Z096), and Foundation from Xi'an University of Technology (Grant No. 106-451619016). The authors would like to express their appreciation to the agencies.

\section{References}

1. Zhao D G. Research on the development prospect of Ansai waist drum from the perspective of intangible cultural heritage protection [J]. Journal of Shaanxi university of science and technology (natural science edition), 2011, 29 (3) : 183-186.

2. Wang T J,Fan L H,Wang H L. Shaanxi Ansai waist drum carry out and its inheritance and development research[J]. Journal of zhejiang sports science, 2016, 20 (3) : 54-55 + 92.

3. Zhu X F. Research on the development status and countermeasures of Ansai waist drum[J]. Journal of Zhangzhou Normal University (natural science edition), 2007 (04) : 125-128.

4. Gao P F. Study on the historical changes and inheritance of waist drum movement in northern Shaanxi -- a case study of Ansai and Hengshan waist drum[J]. Sports and science,2014,35(03):7882.

5. Yuan L. The history and present of the Japanese cultural heritage protection movement[J]. Northwest ethnic studies,2014(2):132-138.

6. Marcello Carrozzino, Alessandra Scucces, Rosario Leonardi, et al. Virtually preserving the intangible heritage of artistic handicraft [J]. Journal of Cultural Heritage, 2011(12):82-87.

7. Jacky C.R Chan, Howard Leung, Jeff K.T. Tang, et al. A Virtual Reality Dance Training System Using Motion Capture Technology [J]. IEEE Transactions on learning technologies.2011,4(2):187-195.

8. Shi L. Digital protection of intangible cultural heritage dance by motion capture technology[D]. Yunnan Arts University,2015.

9. Yu T. Based on motion capture digital protection research of tai chi chuan[D].National Sun Yat-sen University,2013. 